\title{
Glucocorticoids decrease $c$-fos expression in human nasal polyps in vivo
}

\author{
James N Baraniuk, Godfrey Wong, Mushtaq Ali, Marybeth Sabol, Thomas Troost
}

\begin{abstract}
Background-Activated c-fos binds to jun proteins to form the activation protein 1 $(A P-1)$ transcription factor that regulates cytokine and other proinflammatory genes. c-Fos may play a key role in nasal polyp formation. Glucocorticoids may exert their anti-inflammatory effects through an interaction of glucocorticoid receptors with $A P-1$ that leads to mutual inactivation of both factors, and a "default" termination of $A P-1$ mediated gene activation. This may explain the beneficial effects of glucocorticoids in the treatment of nasal polyps.
\end{abstract}

Methods-To test this hypothesis in humans in vivo the immunohistochemical expression of $c$-fos-immunoreactive material (c-fos-irm) was assessed in nasal polyps from eight steroid naive subjects, polyps from eight subjects treated with topical beclomethasone dipropionate (BDP), and normal inferior turbinate nasal mucosa $(n=6)$.

Results-mRNA for $c$-fos was detected in all nasal polyps and normal mucosa. In contrast, $c$-fos-irm was present in all steroid naive subjects but in only two of the eight subjects treated with BDP $(p=0.007$, two-tailed Fisher's exact test). c-Fos-irm was expressed solely in epithelial cells and glandular structures; it was expressed in normal epithelium and glands, but the staining intensity was low.

Conclusion-Glucocorticoids appear to modulate expression of $c$-fos-irm and possibly $A P-1$ in human airway epithelial cells in vivo.

(Thorax 1998;53:577-582)

Keywords: glucocorticoids; $c$-fos; $A P-1$; epithelial cells; nasal polyps

Nasal polyps are known to express high levels of proinflammatory transcription factors such as $c$-fos. ${ }^{1}$ The $c$-fos oncogene participates in transduction cascades that are initiated by many proinflammatory mediators. ${ }^{2} c-F o s$ combines with members of the $c-j u n$ family to form the transcription factor activation protein 1 $(A P-1)$. AP-1 moves from the cytoplasm into the nucleus where it binds to $A P-1$ promoter sites on a wide variety of genes. $A P-1$ helps initiate transcription of many proinflammatory genes, including those for cytokines.

One mechanism of glucocorticoid action is postulated to be an interaction with $c$-fos or $A P-1 .^{3-6}$ Glucocorticoids enter cells and bind to glucocorticoid receptors. These activated re- ceptors are thought to bind to activated $A P-1$, leading to mutual inactivation of both protein factors. This reduction in the amount of free activated AP-1 may lead to a "default" reduction in the expression of genes that require $A P-1$ for activation. ${ }^{3-5} 78$ Hence, synthesis of mRNAs for many proinflammatory products may become reduced. ${ }^{9}{ }^{10}$

A human model would be useful for studying this postulated interaction between glucocorticoid and $c$-fos and to learn its relevance to the actions of glucocorticoids in vivo. Since Emery et $a l^{1}$ noted the presence of $c-f o s, c-j u n$, and $c-m y c$ mRNA in human nasal polyps it has been of interest to determine the distribution of $c-f o s$ immunoreactive material ( $c$-fos-irm) in nasal polyps and the effects of glucocorticoids on $c$-fos-irm and mRNA expression in vivo. It was hypothesised that $c$-fos-irm would be expressed as a marker of cellular activation in polyps, but that glucocorticoid treatment would reduce the levels of expression. Nasal polyps from steroid treated and steroid naive subjects were examined by immunohistochemistry and reverse transcriptase-polymerase chain reaction (RTPCR).

\section{Methods}

NASAL TISSUES

Subjects with refractory nasal obstruction due to nasal polyposis underwent polypectomy. Patient diagnoses, allergy status (determined by clinical and allergy skin test parameters) and medications were noted (table 1). Inferior turbinates were obtained from six subjects who underwent surgery for nasal septal deviation and jaw deformity. This tissue served as a source of normal nasal mucosa. Cases were coded to provide confidentiality. Tissues were immediately frozen in liquid nitrogen and stored at $-70^{\circ} \mathrm{C}$. A portion was frozen in OCT for cryostat sectioning.

Immunohistochemical analysis and RT-PCR were performed to detect $c$-fos immunoreactive material (c-fos-irm) and mRNA, respectively. Clinical histories were reviewed and individual cases were sorted into two groups: those who had never received glucocorticoids or had received none in the past three months (steroid naive) and those who had received any topical nasal or oral steroid in the past three months (steroid treated).

IMMUNOHISTOCHEMISTRY

Cryostat sections $(4 \mu \mathrm{m})$ were cut onto silanated glass slides and stored at $-20^{\circ} \mathrm{C}$. Slides were heated to $4^{\circ} \mathrm{C}$ for five minutes, then to room temperature before washing in phosphate buffered saline (PBS) twice for five minutes each.
6 March 1998

Accepted for publication

31 March 1998 

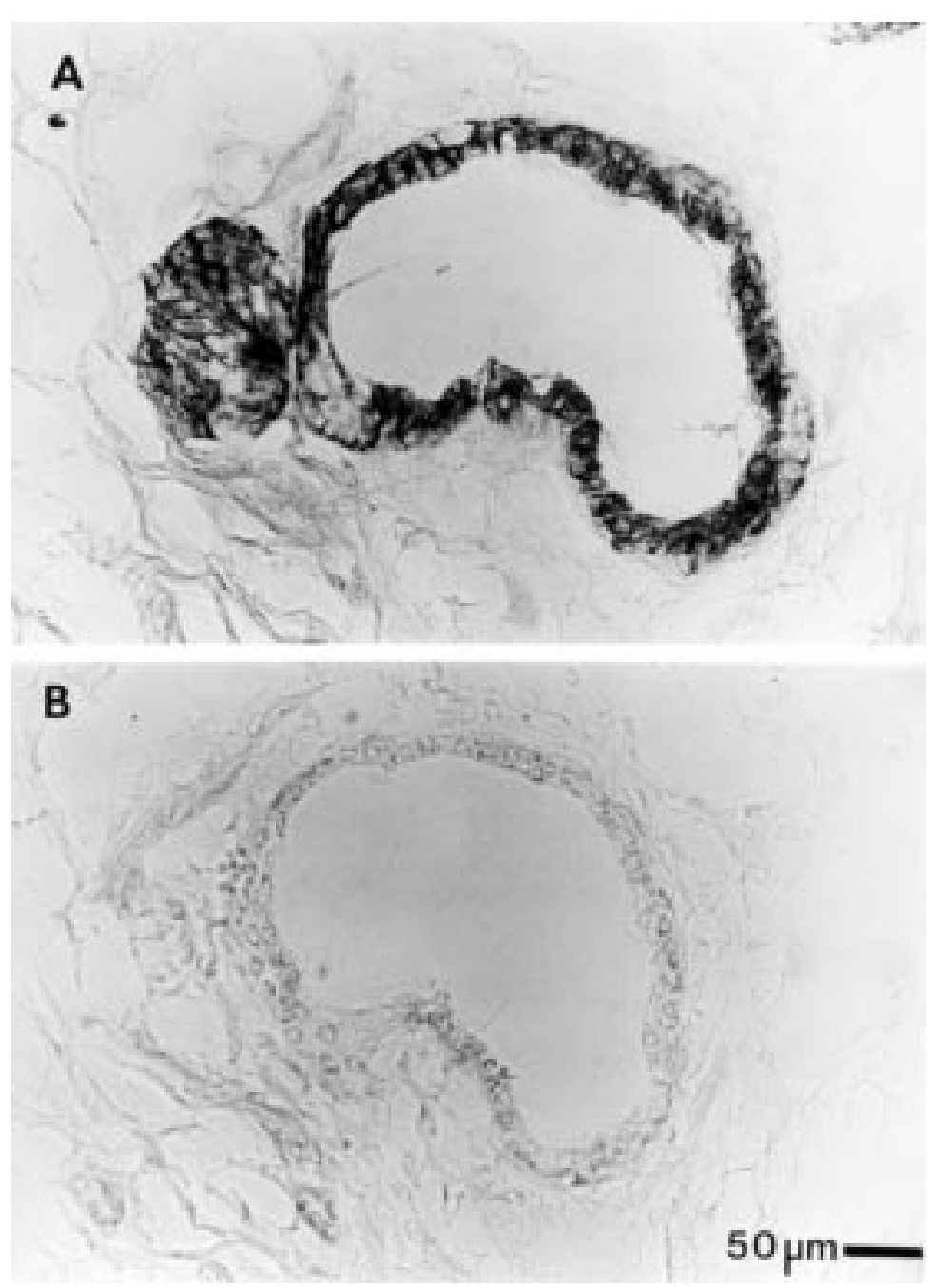

Figure 1 c-Fos-irm in nasal polyps. (A) c-Fos-irm in gland and duct cytoplasm in a nasal polyp from a subject never treated with steroids. (B) Non-immune serum control.
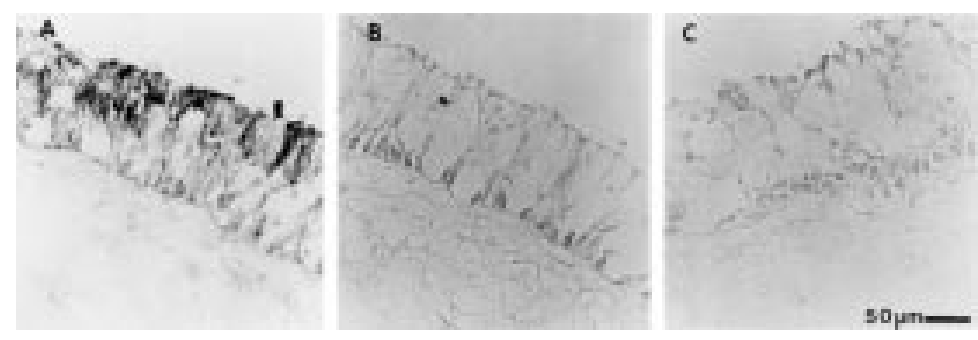

Figure 2 c-Fos-irm in nasal polyps. (A) Steroid naive subject with c-fos-irm in epithelial cell cytoplasm. (B) Non-immune serum control of a consecutive section. (C) BDP treated subject with no detectable c-fos-irm.

Endogenous peroxidase activity was destroyed in $0.03 \%$ hydrogen peroxide in methanol for 30 minutes at room temperature. The slides were rinsed gently with distilled water, then washed with PBS twice for five minutes each. Endogenous biotin was blocked (Dako Biotin Blocking System X590) by: (1) adding avidin solution (\#1) for 10 minutes, (2) washing with PBS twice for five minutes each, (3) adding "Biotin Solution \#2" for 10 minutes, and (4) washing with PBS twice for five minutes each. Non-specific binding sites were blocked with Dako blocking buffer for five minutes. Polyclonal rabbit antiserum specific for human fos (Caltag, San Francisco, CA, USA) diluted
$1: 300$ in $2 \%$ BSA was added, and slides incubated overnight at $4^{\circ} \mathrm{C}$ in a humidified chamber. Non-immune rabbit serum was used as a negative control.

Slides were washed with PBS three times for 10 minutes each, then biotinylated goat anti-rabbit IgG (Dako LSAB Kit, Peroxidase, K684) was added for 10 minutes. After washing in PBS twice for five minutes each, streptavidin-peroxidase was applied for 10 minutes. After washing twice with PBS for five minutes each, AEC chromogen (Dako) was applied for exactly 40 seconds, then immediately rinsed with distilled water. Slides were mounted with Crystal/Mount (Biomeda), air dried, and baked at $80^{\circ} \mathrm{C}$ for 10 minutes. After cooling, slides were coverslipped with Permount (Fisher).

Slides from steroid naive polyps known to have positive $c$-fos-irm staining and from steroid treated polyps known to have negative $c$-fos-irm staining were always included as positive and negative controls when new polyp sections were stained. The distribution of $c$-fos-irm staining was observed by light microscopy, but was not scored for relative intensity because of concerns about adequate quantitative standards. Therefore, $c$-fos-irm staining was scored as either present or absent.

The proportions of $c$-fos-irm positive polyps in the two subject groups were compared by Fisher's exact test with probability quoted for two tailed comparisons.

POLYP INCUBATION IN VITRO

Nasal polyps from steroid naive subjects were cut into $4 \times 4 \mathrm{~mm}$ fragments and cultured in 2 ml CMRL-1066 (Biofluids, Rockville, MD, USA) with or without $1 \mu \mathrm{M}$ dexamethasone in CMRL-1066 in 5\% $\mathrm{CO}_{2}$, room air ${ }^{11}$ for 24 hours before being frozen in OCT in liquid nitrogen. Expression of $c$-fos-irm was determined in fresh frozen, media-treated, and dexamethasone-treated polyps.

\section{RNA EXTRACTION}

Fresh or frozen nasal polyp tissues $(4 \times 4 \mathrm{~mm})$ were placed in sterile Eppendorf tubes, $1 \mathrm{ml}$ of Tri-Reagent (Molecular Research Corporation, Cincinnati, OH, USA) was added, and homogenised at room temperature. ${ }^{12}$ Chloroform $(0.2 \mathrm{ml})$ was added and the two phases were separated by centrifugation at $12000 \mathrm{~g}$ for 10 minutes. The top RNA-containing layer was removed to a fresh tube, $0.5 \mathrm{ml}$ isopropanol was added, and the contents were gently mixed for 15 minutes. After centrifugation at $12000 \mathrm{~g}$ for 30 minutes the pellet was washed with $70 \%$ ethanol and again spun at $12000 \mathrm{~g}$ for $30 \mathrm{~min}$ utes. The RNA pellet was resuspended in 10 $\mathrm{ml}$ diethylpyrocarbonate treated water and used immediately for RT-PCR.

\section{PRIMERS}

$\beta$-Actin primers were purchased from Clontech (Palo Alto, CA, USA). The primers ${ }^{13} 14$ generated an RT-PCR product 661 bases long from mRNA, but 867 bases long from genomic DNA because of the presence of a short intron. $\beta$-actin mRNA was used as a positive control in 
Table 1 Subject characterisation and results of c-fos immunohistochemical analysis

\begin{tabular}{|c|c|c|c|c|c|c|c|c|c|}
\hline \multirow[b]{2}{*}{ Subject } & \multirow[b]{2}{*}{ Age } & \multirow[b]{2}{*}{ Sex } & \multicolumn{2}{|c|}{ Steroid treatment } & \multirow[b]{2}{*}{ Atopy } & \multirow{2}{*}{$\begin{array}{l}\text { Aspirin } \\
\text { sensitive }\end{array}$} & \multirow[b]{2}{*}{ Asthma } & \multicolumn{2}{|l|}{ c-Fos-irm } \\
\hline & & & Topical & Oral & & & & Epithelium & Gland \\
\hline \multicolumn{10}{|c|}{ Nasal polyps from steroid naive subjects } \\
\hline A & 64 & M & No & No & No & No & No & + & + \\
\hline $\mathrm{J}$ & 61 & $\mathrm{M}$ & No & No & Pollens & No & No & + & + \\
\hline $\mathrm{K}$ & 54 & $\mathrm{~F}$ & No & No & Penicillin & No & No & + & + \\
\hline $\mathrm{N}$ & 20 & M & No & No & No & No & No & + & + \\
\hline $\mathrm{O}$ & 45 & M & No & No & Cortisone & Yes & No & + & $\mathrm{NP}$ \\
\hline $\mathrm{P}$ & 43 & M & No & No & Pollen/dust & No & Yes & + & NP \\
\hline Q & 52 & M & No & No & Pollen/dust & No & Yes & + & NP \\
\hline $\mathrm{R}$ & 62 & $M$ & No & No & Pollen & No & No & + & + \\
\hline \multicolumn{10}{|c|}{ Nasal polyps from steroid treated subjects } \\
\hline B & 43 & $\mathrm{M}$ & $\mathrm{BDP}$ & No & No & No & No & 0 & 0 \\
\hline $\mathrm{C}$ & 25 & $\mathrm{M}$ & BDP & No & No & No & No & 0 & 0 \\
\hline $\mathrm{E}$ & 55 & M & BDP & No & No & No & Yes & 0 & 0 \\
\hline $\mathrm{F}$ & 49 & $\mathrm{~F}$ & BDP & No & No & No & No & 0 & 0 \\
\hline $\mathrm{D}$ & 28 & $\mathrm{~F}$ & $\mathrm{BDP}$ & No & Seafood & No & No & 0 & 0 \\
\hline $\mathrm{G} 1$ * & 64 & $\mathrm{~F}$ & $\mathrm{BDP}$ & Pred & Pollen/dust & Yes & Yes & 0 & 0 \\
\hline $\mathrm{G} 2$ * & & & $\mathrm{BDP}$ & No & Pollen/dust & Yes & Yes & 0 & 0 \\
\hline $\mathrm{G} 3^{\star}$ & & & BDP & No & Pollen/dust & Yes & Yes & + & $\mathrm{NP}$ \\
\hline $\mathrm{H}$ & 80 & $\mathrm{M}$ & Dex & No & No & No & No & 0 & 0 \\
\hline I & 49 & $\mathrm{M}$ & No & Medrol† & Pollens & Yes & Yes & + & 0 \\
\hline $\mathrm{L}$ & 54 & $\mathrm{M}$ & Dex & No & Pollen/dust & Yes & Yes & 0 & 0 \\
\hline M & 57 & M & BDP & No & No & No & No & + & NP \\
\hline \multicolumn{10}{|c|}{ Inferior turbinate mucosa } \\
\hline $\mathrm{T} 1$ & 67 & $\mathrm{~F}$ & BDP & No & Pollen & No & No & + & + \\
\hline $\mathrm{T} 2$ & 60 & M & No & No & Pollen/dust & No & No & + & + \\
\hline T3 & 18 & $\mathrm{~F}$ & No & No & No & No & No & + & + \\
\hline $\mathrm{T} 4$ & 36 & $\mathrm{~F}$ & No & No & No & No & No & + & + \\
\hline T5 & 33 & M & $\mathrm{BDP}$ & No & No & No & No & + & + \\
\hline T6 & 44 & $\mathrm{~F}$ & No & No & Pollen & No & No & + & + \\
\hline
\end{tabular}

$\mathrm{BDP}=$ beclomethasone dipropionate $168 \mu \mathrm{g} /$ nostril/day (Beconase, Beconase AQ, Vancenase AQ, Vancenase Pockethaler); NP = glands not present in this specimen; Dex = dexamethasone ophthalmic drops; Pred = prednisone (Medrol, methylprednisolone); $0=$ absent; $+=$ present. ${ }^{\star}$ One subject had three polypectomies. $†$ Seven days treatment only.

all RT-PCR reactions to ensure that intact mRNA was present and that there was no DNA contamination.

$c$-Fos primers were synthesised by the Lombardi Cancer Center Core Laboratory. ${ }^{15}$ The sense primer (5'-TGC CAA CTT CAT TCC CAC GGT) coded for nucleotides 1212-1232 in exon 2. The antisense primer (5'-TAG TTG GTC TGT CTC CGC TTG) was complementary to the mRNA sequence which spanned the exon 3-4 splice site $\left(\mathrm{C}^{\text {ntd }}\right.$

AA GCG GAG ACA GAC $\mathrm{C}^{\text {ndd }}{ }^{2102}$ ). The RT-PCR product from mRNA was 347 bases long, and no product could be synthesized from genomic DNA.

$Z O-1$ mRNA, which codes for the protein that forms epithelial tight junctions, was used as a positive control to demonstrate the presence of epithelial cells in nasal polyp RNA preparations. This was necessary to ensure that mRNA from epithelial cells (the site of $c$-fos immunoreactive material) was present in polyp RNA preparations. $Z O-1$ sense $\left(5^{\prime} \mathrm{C}^{\text {ntd }}{ }^{10} \mathrm{AT}\right.$ AGA ATA GAC TCC CCT GG ${ }^{\text {nd }}{ }^{30}$ ) and antisense $\left(5^{\prime} \mathrm{C}^{\text {ndd }}{ }^{443} \mathrm{TG}\right.$ CTG GCT TGT TTC TCT $\mathrm{AC}^{\text {ntd }}{ }^{423}$ ) primers $^{1617}$ were synthesised. Two alternatively spliced $Z O-1 \mathrm{mRNAs}$ are present in epithelial cells and represent a full length mRNA coded by at least three exons

Table 2 Comparisons of c-Fos-irm immunohistochemistry in nasal polyp epithelium from steroid naive and steroid treated subjects

\begin{tabular}{lclll}
\hline \multirow{3}{*}{ Group } & \multirow{3}{l}{$c$-Fos staining } & \multirow{2}{*}{$\begin{array}{l}\text { p value (Fisher's exact } \\
\text { two-tailed test) }\end{array}$} \\
\cline { 3 - 4 } & No & Present & Absent & \\
\hline Steroid naive subjects & 8 & 8 & 0 & 0.004 \\
Steroid treated subjects & $10^{\star}$ & 3 & 7 & 0.0014 \\
$\quad$ Polyps & $12^{\star}$ & 3 & 9 & 0.007 \\
$\quad$ Topical BDP & 8 & 2 & 6 & \\
\hline
\end{tabular}

^ One subject had three polypectomies. and a shorter mRNA with the second putative exon ("motif a", 240 nucleotides) deleted. The RT-PCR products from these mRNAs were 433 and 193 nucleotides long, respectively.

QUALITATIVE RT-PCR

RNA, reverse transcriptase/antisense primers, and Perkin Elmer RT-PCR reagents (Norwalk, $\mathrm{CN}$, USA) were mixed according to manufacturer's recommendations at $4^{\circ} \mathrm{C}$ in a $\mathrm{PE}$ thermocycler. Mineral oil $(70 \mu \mathrm{l})$ was added and the temperature increased to $42^{\circ} \mathrm{C}$ for 60 minutes to anneal the RT/antisense primer to specific mRNA sequences. The solution was denatured at $99^{\circ} \mathrm{C}$ for five minutes and cooled to $70^{\circ} \mathrm{C}$.

Perkin Elmer taq, buffer, $\mathrm{Mg}^{2+}$, and sense primers were preheated to $70^{\circ} \mathrm{C}$ and added to each reversely transcribed tube ("Hot-Start" conditions that reduce non-specific priming). To permit efficient annealing and extension for this first cycle of PCR, the temperature was adjusted to $57^{\circ} \mathrm{C}$ and maintained for five minutes. This was followed by extension for two minutes at $72^{\circ} \mathrm{C}$. Annealing temperatures were calculated according to Meinkoth and Wahl. ${ }^{18}$ Tubes were cycled for a total of 45 cycles of $94^{\circ} \mathrm{C}$ for one minute, $57^{\circ} \mathrm{C}$ for one minute, and $72^{\circ} \mathrm{C}$ for two minutes. This number of cycles is required because of the low yield of RNA from polyp fragments.

PCR products and Clontech DNA standards were run in $0.5 \times \mathrm{TBE}$ on $2 \%$ agarose (FMC, Rockland, ME, USA) for 1.5 hours at $120 \mathrm{~V}$. Gels were stained with ethidium bromide and the bands were visualised by UV fluorescence and photographed with Polaroid 667 film. Photographs of UV fluorescence patterns from representative gels were scanned (Aldus 

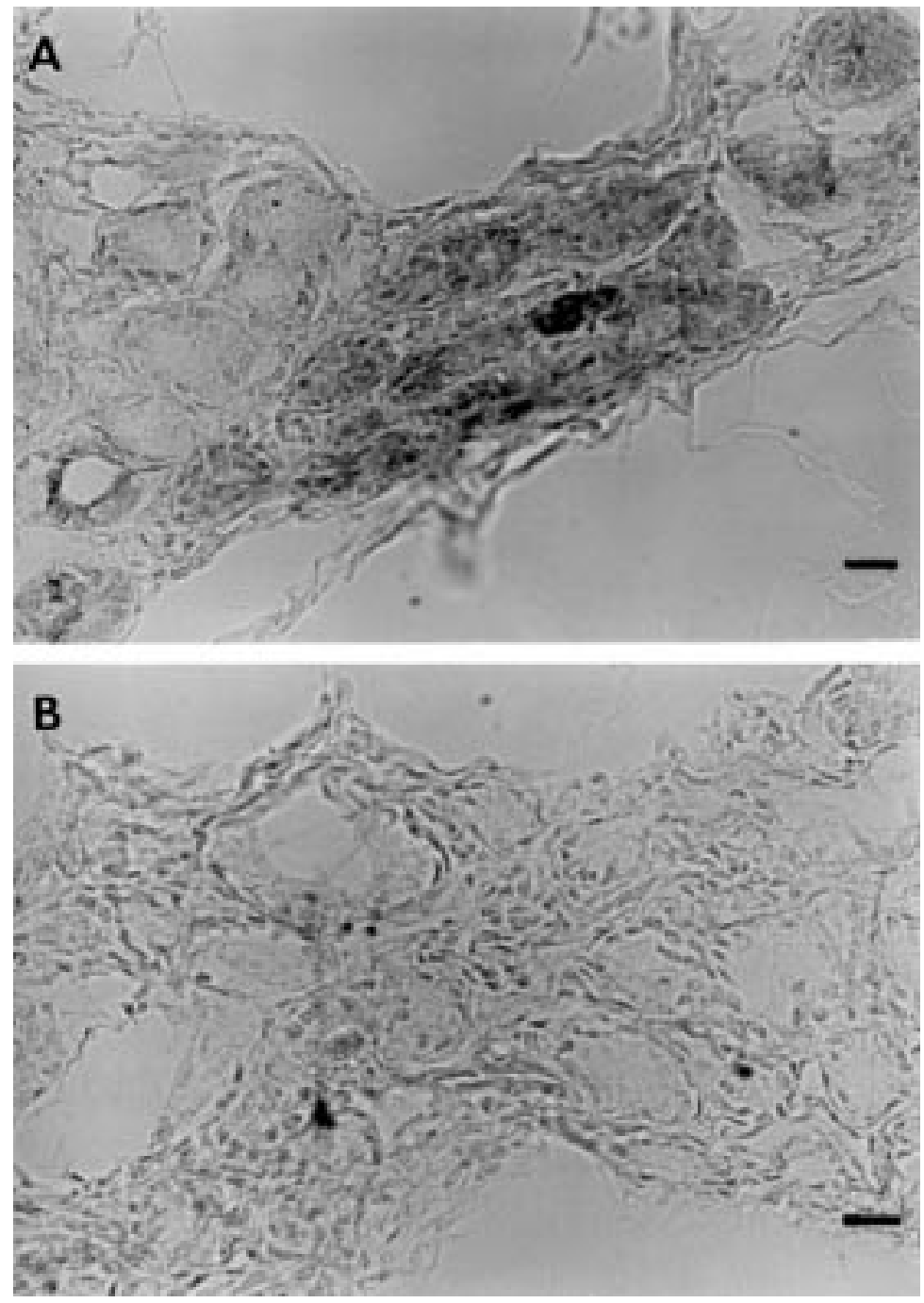

Figure 3 c-Fos-irm in human nasal submucosal glands. (A) Steroid naive subject with gland cells showing either intense or relatively weak staining. (B) Non-immune serum control with no staining. Bars represent $50 \mu \mathrm{m}$.

Photostyler 2.0 for Windows, Aldus, Seattle, WA, USA) and positive and negative images were compiled (Corel Draw 4.0, Corel Corp, Toronto, Ontario, Canada) and laser printed.

\section{Results}

IMMUNOHISTOCHEMISTRY

c-Fos-irm was present in nasal polyps of steroid naive patients (figs 1 and 2, table 1). Epithelial cells, particularly those cells with cytoplasm in the most superficial half of the epithelial thickness, were the predominant site of expression. There were very few glands in polyps; glandlike structures had the appearance of invaginated epithelial tubes lined with cuboidal epithelial cells. When present in steroid naive subjects, these "glandular" cells were invariably positive for $c$-fos-irm.

$c$-Fos-irm was absent in nine of 12 polyps from subjects who were currently taking oral or topical glucocorticoids. This ratio was significantly different from that for steroid naive subjects $(p=0.0014)$, suggesting that glucocorticoid use contributed to the difference in $c$-fos-irm expression (table 2). Treatment with topical beclomethasone dipropionate (BDP)

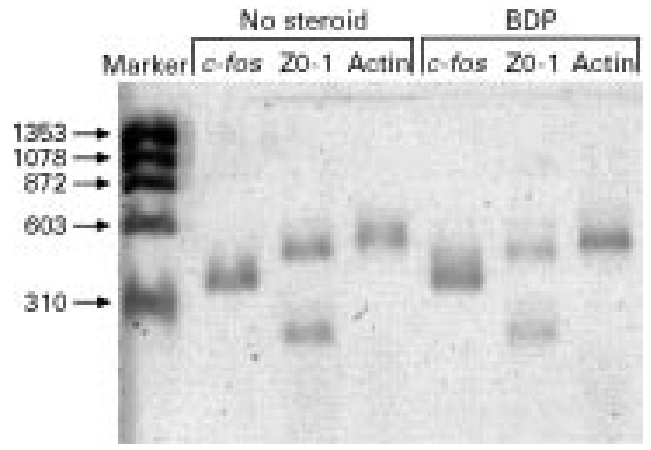

Figure 4 Qualitative RT-PCR of $\beta$-actin, ZO-1, and $c$-fos in human nasal polyp $m R N A$ s from a steroid naive subject (subject $\mathcal{F}$ ) and a subject treated with BDP (subject L).

for at least three months significantly reduced $c$-fos-irm expression $(\mathrm{p}=0.007)$.

Only $30 \%$ of the subjects on glucocorticoids had $c$-fos-irm expression in nasal polyps (tables 1 and 2). In general the staining was less intense than in the steroid naive subjects, but semiquantitative immunohistochemistry was not performed to assess differences. One subject $(\mathrm{G})$ had three polypectomies $(\mathrm{G} 1, \mathrm{G} 2$, G3) with $c$-fos-irm detectable in G3 while on topical BDP alone. Subject I had severe chronic sinusitis complicating nasal polyposis but had received oral methylprednisolone for only seven days prior to surgery. More than seven days of oral treatment may be necessary to dampen $c$-fos-irm expression. Staining in this subject was weak. Weak staining was also found for subject $M$ who was treated with topical BDP. $c-F o s$-irm was absent in $75 \%$ of the polyps from subjects treated with topical BDP.

In all of the inferior turbinate control tissues $c$-fos-irm was present in the superficial cells of the epithelium and a fraction of the submucosal gland cells (fig 3 ). The pattern of staining of epithelial cells was similar to that in nasal polyps (fig 2) but the staining was less intense. Basal cells had no staining in some sections. Submucosal gland cells were the only cells with detectable staining in the lamina propria.

POLYP INCUBATION

Culture of polyps from steroid naive subjects for 24 hours in $1 \mu \mathrm{M}$ dexamethasone did not reduce $c$-fos-irm expression. Longer periods of glucocorticoid treatment may be necessary to alter expression of $c$-fos-irm. However, culture conditions may activate cells, induce $c$-fos-irm expression, and confound these experiments.

\section{QUALITATIVE RT-PCR}

$\beta$-Actin mRNA was present, indicating extraction of intact RNA from nasal polyps of steroid naive $(\mathrm{A}, \mathrm{J}, \mathrm{K}, \mathrm{N}, \mathrm{O})$ and steroid treated $(\mathrm{B}, \mathrm{C}$, G2, G3, L) subjects (fig 4). There was no DNA contamination since the single bands were at the size predicted for mRNA transcripts and not at the size predicted for genomic DNA.

ZO-1 mRNA was present in all the polyps, indicating the presence of epithelial cells. Therefore, it was possible for $c$-fos $\mathrm{mRNA}$ to be present since these were the cells that expressed c-fos immunoreactive material. Both the 433 and 193 nucleotide $Z O-1 \mathrm{mRNAs}$ were detected in all samples. 


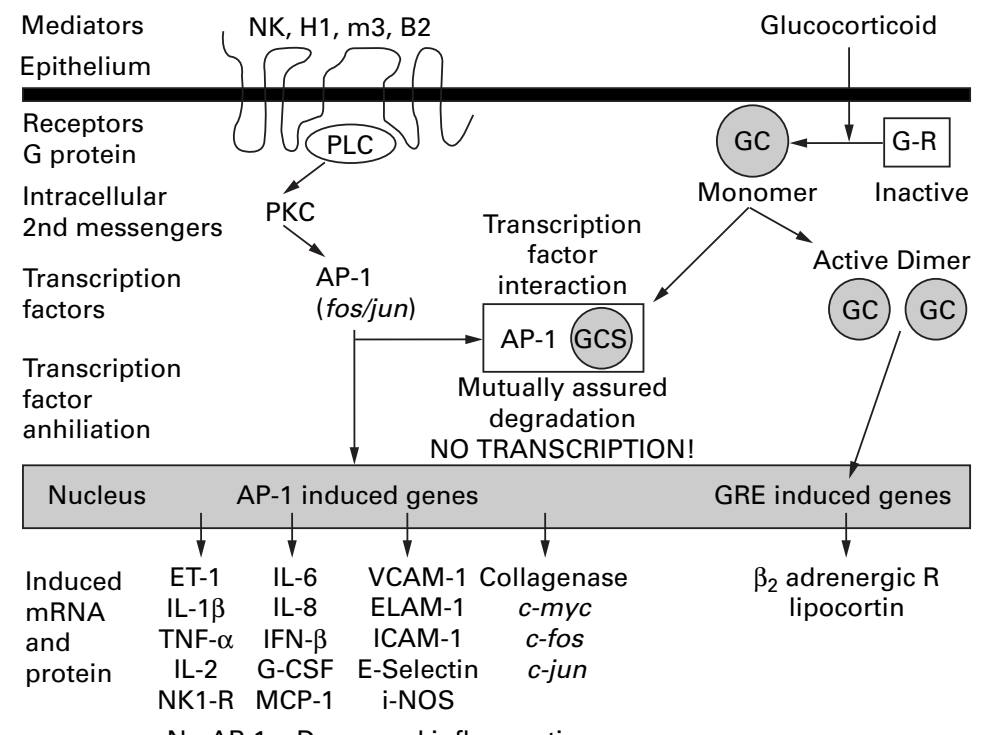

Figure 5 Hypothesis of c-Fos/AP-1 interactions with glucocorticoids. Activation of neurokinin (NK), histamine H1, muscarinic m3, bradykinin B2, and other 7-transmembrane receptors leads to the activation of c-fos and c-jun, and the formation of AP-1 (left side). AP-1 participates in the induction of a wide variety of proinflammatory proteins, receptors, and mediators. Glucocorticoids bind to cytoplasmic receptors which dimerise and translocate to the nucleus to induce genes such as the $\beta_{2}$ adrenergic receptor (right side). AP-1 and activated glucocorticoid receptors can bind to each other, leading to their mutual proteolytic degradation and the loss of their nuclear transcription factor effects. The current study supports this hypothesis since nasal steroids reduced the expression of epithelial c-fos-irm. ticoid receptors can bind to each other, leading to their mutual proteolytic degradation and the loss of their nuclear transcription factor effects. The current study supports this hypothesis since nasal steroids reduced the expression of epithelial $c$-fos-irm.

The findings of this study indicate that $c$-fos mRNA was transcribed in nasal polyps from all subjects and in normal nasal mucosa. c-fos mRNA was translated into $c$-fos protein (c-fosirm). In nasal polyps from steroid naive subjects epithelial and glandular cells stained intensely with $c$-fos-irm. In contrast, after steroid treatment in vivo staining was absent or was of low intensity. Higher intensity staining occurred in subjects with more extensive nasal and sinus disease, or in those who had been treated for shorter periods of time-for example, seven days of methylprednisolone in subject I. Twelve weeks of topical BDP was effective in reducing $c$-fos-irm expression, confirming the rationale for direct topical treatment of respiratory diseases.

The continuing presence of $c$-fos mRNA with reduced expression of $c$-fos-irm expression after steroid treatment could be due to (a) continued transcription of $c$-fos mRNA but with reduced translation into $c$-fos-irm protein, (b) increased turnover of $c$-fos-irm protein such that levels were not detectable by immunohistochemistry, or (c) binding of activated glucocorticoid receptor monomers and $c$-fos-irm $/ A P-1$ leading to the mutual inactivation, proteolytic degradation, and the loss of both the $c$-fos-irm and glucocorticoid receptors. The latter is most consistent with current hypotheses of glucocorticoid actions (fig 5). However, the qualitative amplification protocol was not designed to detect differences between sets, so partial reductions in mRNA expression could have occurred and not been detected. Much more $c$-fos mRNA is detected by RNase protection assay in polyps than in other human nasal mucosa tissues. ${ }^{1}$

The epithelial localisation suggests that the $A P-1$ transcription factor plays an important role in epithelial cells and may significantly contribute to the pathology of nasal polyposis. $A P-1$ induces many mRNAs for proinflammatory proteins, including cytokines, that could initiate or promulgate mucosal inflammation. ${ }^{6-10} 1920$ Alternatively, epithelial cells could be "innocent bystanders" that are activated by mast cell or eosinophil factors: $c$-fos expression would be a marker of cell activation. However, the production of eotaxin, RANTES, GM-CSF, IL-8 and other cytokines by epithelial cells suggests a more integral role. ${ }^{19} 20$

There was a striking absence of $c$-fos-irm expression in fibroblasts, endothelium, and inflammatory cells. This suggests that $c-f o s / A P$ 1 mediated events may be more important in the epithelium than these other cell populations, or that epithelial cells maintain a large "reservoir" of non-activated but immunoreactive $c$-fos that could be available for immediate cellular activation. Alternatively, $c$-fos-irm could be present and active, yet still be below the limits of immunohistochemical detection. 
Low intensity $c$-fos-irm staining was also present in inferior turbinate mucosa epithelium and gland cells. Demoly et al have described similar low intensity staining in bronchial epithelium. ${ }^{21}$

Some of the subjects had recurrences of their nasal polyps despite treatment with topical glucocorticoids. This indicates that, although glucocorticoids may interfere with $A P-1$ and reduce polyp growth, there are still subjects who do not respond and require polypectomy. This implies the presence of steroid nonresponsive mechanisms that contribute to this mucosal inflammatory state. This hypothesis is supported by Norlander et al who found that treatment with nasal budesonide spray (200 or $400 \mu \mathrm{g}$ twice per day, Rhinocort Aqua, Astra, Lund, Sweden) for eight weeks did not alter the expression of mRNA for glucocorticoid receptor, IL-1 $\beta$, IL-2, IL-4, IL-5, IL-6, IL-10, $\mathrm{TNF}-\alpha$, or interferon- $\gamma$ in polyps from patients with refractory nasal polyposis. ${ }^{22}$ Other cytokines such as IL-13 may be responsible since they can induce steroid resistance. ${ }^{23}$

As already mentioned, there are several limitations to this study that can be rectified in future investigations. A placebo controlled comparison showing the expression of $c$-fos mRNA, $c$-fos-irm, and protein function after treatment with nasal steroids is warranted. However, the dose and duration of treatment remains to be established. Polyps may disappear with treatment, leaving no tissue for posttreatment analysis. Responses in aspirin sensitive and insensitive polyp patients should be compared. These in vivo studies suggest that the dramatic modulatory effects of glucocorticoids that can be readily demonstrated by reductionist in vitro experiments of purified or cultured lymphocytes, epithelial, or other cells may not predict mucosal effects in complex disease states. The qualitative RT-PCR confirmed the presence of epithelial cell mRNA $(Z O-1)$ and the expression of $c$-fos mRNA in the epithelium, but this method should not be considered quantitative. Studies of the transcriptional and translational control c-fos expression, $c$-fos-glucocorticoid receptor interactions, and $c$-fos turnover need to be established in model systems since there is insufficient protein and mRNA in polyps to develop these methods de novo. These experiments provide human in vivo evidence to support the hypothesis that activated glucocorticoid receptors can interact with $c$-fos and the $A P-1$ transcription factor and suggest that this interaction may contribute to the beneficial effects of glucocorticoids.
This study was supported by a research grant from GlaxoWellcome Research, Research Triangle Park, North Carolina, USA.The authors would like to give special thanks to Mark Osterman for his assistance.

1 Emery B, Baraniuk JN, Minna J, et al. Proto-oncogene expression in human nasal polyposis. F Allergy Clin Immunol 1990;85:225.

2 Angel P, Karin M. The role of jun, fos, and the AP-1 complex in cell proliferation and transformation. Biochem Biophys Acta 1991;1072:129-57.

3 Jonat C, Rahmsdorf HJ, Park KK, et al. Antitumor promotion and anti-inflammation: down-modulation of AP-1 (fos/jun) activity by glucocorticoid hormone. Cell 1990;62: 1189-204

4 Yang-Yen HF, Chambard JC, Sun YL, et al. Transcriptional interference between c-jun and the glucocorticoid receptor: mutual interaction of DNA binding due to direct protein-protein interaction. Cell 1990;62:1205-15.

5 Schule R, Rangarajan P, Kilewer S, et al. Functional antagonism between oncoprotein c-jun and the glucocorticoid receptor. Cell 1990;62:1217-26.

6 Baraniuk JN. Glucocorticoids: bench to bedside. I Allergy Clin Immunol 1996;97:141-82.

7 Adcock IM, Brown CR, Peters MJ, et al. DNA binding of Adcock IM, Brown CR, Peters MJ, et al. DNA binding of
glucocorticoid receptor from peripheral blood monocytes of steroid sensitive and resistant patients. Am Rev Respir Dis 1993;147:A244.

8 Adcock IM, Brown CR, Virdee H, et al. Transcription factor interactions in peripheral blood monocytes of steroid sensitive and resistant asthmatic patients. Am Rev Respir Dis 1993;147:A292.

9 Barnes PJ. Molecular mechanisms of steroid action in asthma. $\mathcal{F}$ Allergy Clin Immunol 1996;97:159-68.

10 Paliogianni F, Raptis A, Ahuja SS, et al. Negative transcriptional regulation of human interleukin 2 (IL-2) gene by glucocorticoids through interference with nuclear transcription factors AP-1 and NF-AT. F Clin Invest 1993;91: 1481-9.

11 Shelhamer JH, Marom Z, Kaliner MA. Immunologic and neuropharmacologic stimulation of mucous glycoprotein release from human airways in vitro. $\mathcal{F}$ Clin Invest 1980;66: release from-8.

12 Chomczynski P. A reagent for the single-step simultaneous isolation of RNA, DNA and proteins from cell and tissue isolation of RNA, DNA and proteins
samples. Biotechniques 1994;15:532-6.

13 Pinte P, Ng SY, Engle J, et al. Evolutionary conservation in the untranslated regions of actin mRNAs: DNA sequence of a human 8-actin cDNA. Nucl Acids Res 1984;12:1687-96.

14 Nakajima-Ijima S, Hamada H, Reddy P, et al. Molecular structure of the human cytoplasmic 8-actin gene: interspecies homology of sequences in the introns. Proc Natl Acad Sci USA 1985;82:6133-7.

15 van Straaten F, Muller R, Curran T, et al. Complete nucleotide sequence of a human c-onc gene: deduced amino acid sequence of the human c-fos protein. Proc Natl Acad Sci USA 1983;80:383-7.

16 Willott E, Balda MS, Heintzelman M, et al. Localization and differential expression of two isoforms of the tight junction protein ZO-1. Am f Physiol 1992;262 (Cell Physiol 31): C1119-24.

17 Steiger D, Fahy J, Boushey $\mathrm{H}$, et al. Use of mucin antibodies and cDNA probes to quantify hypersecretion in vivo in human airways. Am $\mathcal{f}$ Respir Cell Mol Biol 1994;10:538-45.

18 Meinkoth J, Wahl G. Hybridization of nucleic acids immobilized on solid supports. Anal Biochem 1984;138: immobilize

19 Kwon OJ, Au BT, Collins PD, et al. Inhibition of interleukin-8 expression by dexamethasone in human cultured airway epithelial cells. Immunology 1994;81:38994.

20 Levine SJ. Bronchial epithelial cell-cytokine interactions in airway inflammation. F Invest Med 1995;43:241-9.

21 Demoly P, Basset-Sequin N, Chanez P, et al. c-Fos proto-oncogene expression in bronchial biopsies of asthmatics. Am F Respir Cell Mol Biol 1992;7:128-33.

22 Norlander T, Henricksson G, Bronnegard M, et al. Effects of topical budesonide treatment on glucocorticoid receptor
mRNA down regulation and cytokine patterns in nasal polyps. In: Norlander T, ed. Aspects of the inflammatory response and formation in the nasal and sinus mucosa. Stockholm: Kongl Carolinska Medico Chirurgiska Institutet, Repro Kongl Carolinska Medico Chirurgis

23 Bronnegard M, Stierna P, Marcus C. Glucocorticoid resistant syndromes: molecular basis and clinical presentations. $\mathcal{F}$ Neuroendocrinol 1996;8:405-15. 